Western University

Scholarship@Western

Medical Biophysics Publications

Medical Biophysics Department

$2-1-2015$

Rapid desiccation hardening changes the cuticular hydrocarbon profile of Drosophila melanogaster.

Joseph R Stinziano

Richard J Sové

Howard D Rundle

Brent J Sinclair

Follow this and additional works at: https://ir.lib.uwo.ca/biophysicspub

Part of the Medical Biophysics Commons

Citation of this paper:

Stinziano, Joseph R; Sové, Richard J; Rundle, Howard D; and Sinclair, Brent J, "Rapid desiccation hardening changes the cuticular hydrocarbon profile of Drosophila melanogaster." (2015). Medical Biophysics Publications. 45.

https://ir.lib.uwo.ca/biophysicspub/45 


\title{
Rapid desiccation hardening changes the cuticular hydrocarbon profile of Drosophila melanogaster
}

\author{
Joseph R. Stinziano ${ }^{a}$, Richard J. Sové ${ }^{b}$, Howard D. Rundle ${ }^{c}$, Brent J. Sinclair ${ }^{\text {a,* }}$ \\ a Department of Biology, University of Western Ontario, London, ON, Canada \\ ${ }^{\mathrm{b}}$ Department of Medical Biophysics, University of Western Ontario, London, ON, Canada \\ c Department of Biology, University of Ottawa, Ottawa, ON, Canada
}

\section{A R T I C L E I N F O}

\section{Article history:}

Received 12 August 2014

Received in revised form 10 October 2014

Accepted 3 November 2014

Available online 9 November 2014

\section{Keywords:}

Desiccation tolerance

Cuticular permeability

Water loss rate

Phenotypic plasticity

Acute stress response

\begin{abstract}
A B S T R A C T
The success of insects in terrestrial environments is due in large part to their ability to resist desiccation stress. Since the majority of water is lost across the cuticle, a relatively water-impermeable cuticle is a major component of insect desiccation resistance. Cuticular permeability is affected by the properties and mixing effects of component hydrocarbons, and changes in cuticular hydrocarbons can affect desiccation tolerance. A pre-exposure to a mild desiccation stress increases duration of desiccation survival in adult female Drosophila melanogaster, via a decrease in cuticular permeability. To test whether this acute response to desiccation stress is due to a change in cuticular hydrocarbons, we treated male and female $D$. melanogaster to a rapid desiccation hardening $(\mathrm{RDH})$ treatment and used gas chromatography to examine the effects on cuticular hydrocarbon composition. RDH led to reduced proportions of unsaturated and methylated hydrocarbons compared to controls in females, but although RDH modified the cuticular hydrocarbon profile in males, there was no coordinated pattern. These data suggest that the phenomenon of RDH leading to reduced cuticular water loss occurs via an acute change in cuticular hydrocarbons that enhances desiccation tolerance in female, but not male, $D$. melanogaster. (c) 2014 Elsevier Inc. All rights reserved.
\end{abstract}

\section{Introduction}

The success of insects in terrestrial habitats is due in a great part to their ability to tolerate desiccation (Hadley, 1994). The majority of insect water loss is across the cuticle, due to the high surface area to volume ratio (Gibbs, 2002; Hadley, 1994), and reduced rates of cuticular water loss (CWL) are associated with greater resistance to desiccation (Parkash et al., 2008). Cuticular permeability can be modified via structural changes to the cuticle, such as melanisation (Hadley, 1978; Parkash et al., 2009a, 2009b), or through changes to the quantity and identity of cuticular hydrocarbons (CHCs) (Gibbs and Pomonis, 1995). It has been suggested that cuticular permeability can be reduced by increasing total amount, saturation, and chain length of CHCs (Gibbs and Pomonis, 1995). However, an effect of CHC quantity on cuticular permeability and water loss has not always been detected: in tsetse flies, the quantity of $\mathrm{CHCs}$ does not drive variation in cuticular water loss (Jurenka et al., 2007), suggesting that the composition, not quantity, of CHCs may be more important in determining cuticular water loss.

Abbreviations: $\mathrm{CHC}$, cuticular hydrocarbon; $\mathrm{CWL}$, cuticular water loss; $\mathrm{RDH}$, rapid desiccation hardening; $\mathrm{RH}$, relative humidity.

* Corresponding author at: Department of Biology, University of Western Ontario, 1151 Richmond Street, London, ON, Canada N6A 5B7. Tel.: +1 519661 2111x83138; fax: + 1 5196613935.

E-mail addresses: jstinzi@uwo.ca (J.R. Stinziano), rsove@uwo.ca (R.J. Sové), hrundle@uottawa.ca (H.D. Rundle), bsincla7@uwo.ca (B.J. Sinclair).
Similarly in Drosophila melanogaster, while adaptation to desiccation stress in laboratory evolution experiments resulted in no change in total CHC content, the relative concentration of long chain length CHCs increased in two separate studies (Gibbs et al., 1997; Kwan and Rundle, 2010) and this leads to reduced CWL and enhanced survival (Gibbs et al., 1997).

In addition to evolved differences in cuticular permeability, CWL is phenotypically-plastic, changing with acclimation to temperature and humidity (Schimpf et al., 2009; Terblanche et al., 2010), and also during the rapid desiccation hardening response (RDH; Bazinet et al., 2010; Hoffmann, 1991, 1990). Rapid desiccation hardening occurs after a recovery from an initial desiccation stress (Hoffmann, 1990), increasing survival during a subsequent desiccation stress from $\sim 13 \mathrm{~h}$ (no RDH) to $\sim 16 \mathrm{~h}$ (RDH treated) and reducing CWL by $\sim 30 \%$ in female, but not male, D. melanogaster (Bazinet et al., 2010). While both CHC composition and melanisation could reduce CWL, RDH takes place faster than melanisation can occur: within $1 \mathrm{~h}$ as opposed to $6-23 \mathrm{~h}$ for melanisation (Bazinet et al., 2010; Hiruma and Riddiford, 1988). Such a rapid response implicates changes in $\mathrm{CHC}$ composition. While such changes may occur rapidly, they do appear to require a postdesiccation recovery period as few changes in D. melanogaster $\mathrm{CHC}$ content or profiles were observed when individuals were assayed immediately upon extraction from an initial desiccation stress (Kwan and Rundle, 2010). RDH is not accompanied by an increase in CHC quantity in a range of Drosophila species (Kalra et al., 2014), so we 
hypothesized that a change in cuticular hydrocarbon composition is responsible for reduced cuticular water loss during rapid desiccationhardening.

In D. melanogaster, an exposure of $3 \mathrm{~h}$ (male) or $4.5 \mathrm{~h}$ (female) to low humidity followed by $1 \mathrm{~h}$ recovery with access to food and water increased desiccation tolerance (an RDH response) in female, but not male, flies (Bazinet et al., 2010). Bazinet et al. (2010) showed that $\mathrm{RDH}$ reduced cuticular water loss rates and glycogen content; however absolute water content at death was unchanged between control and treated male and female flies. Cuticular water loss can be reduced by both changes to the cuticle structure (e.g. melanin, Kalra et al., 2014), or by changes to cuticular hydrocarbon composition or abundance (e.g. Kwan and Rundle, 2010), but the speed of the change in CWL favours changes to CHCs. Thus the aim of our study was to investigate how desiccation pre-treatment affects the relative composition of $\mathrm{CHCs}$. We predicted that RDH pre-treatment would lead to increased proportions of saturated and longer chain $\mathrm{CHCs}$, and reduced proportions of unsaturated and methyl branched CHCs in female, but not male, $D$. melanogaster. To test this, we used the same population of $D$. melanogaster as in Bazinet et al. (2010), and measured relative CHC concentrations of adult flies with or without an $\mathrm{RDH}$ pre-treatment.

\section{Methods}

\subsection{Fly rearing}

Our D. melanogaster population was established from isofemale lines collected in London, Ontario in 2007 (Marshall and Sinclair, 2010), and was reared according to Bazinet et al. (2010). Briefly, flies were reared at $21.5{ }^{\circ} \mathrm{C}(13: 11 \mathrm{~L}: \mathrm{D}, 50 \% \mathrm{RH})$ on banana-yeast medium (Table S1) in $35 \mathrm{~mL}$ vials (70-100 individuals/vial). Eggs were collected every 14 days in $3.8 \mathrm{~L}$ plastic population cages. We sexed and sorted flies under $\mathrm{CO}_{2}$ within $12 \mathrm{~h}$ of eclosion, remaining consistent with Bazinet et al. (2010). Flies were used for experiments $96 \mathrm{~h}$ post-sorting/ sexing, so that all individuals were ca. four days old at time of experimentation. Experiments were conducted at approximately $21^{\circ} \mathrm{C}$ in a climate-controlled laboratory.

\subsection{Rapid desiccation hardening}

We exposed individual flies to a rapid-desiccation hardening pretreatment as per Bazinet et al. (2010). Briefly, individual flies were transferred to $35 \mathrm{~mL}$ vials and restricted to the lower half via a foam stopper. Approximately $2 \mathrm{~g}$ of silica gel (4-10 mesh; J.T. Baker, Phillipsburg, NJ, USA) was added to the upper portion of the vial, which was then sealed with Parafilm (Pechiney Plastic Packaging, Menasha, WI, USA). Desiccation pre-treatment was $3.0 \mathrm{~h}$ for male flies, and $4.5 \mathrm{~h}$ for female flies to achieve $10 \%$ water loss according to Bazinet et al. (2010), followed by a $1 \mathrm{~h}$ recovery period in a vial with banana-yeast medium prior to cuticular hydrocarbon $(\mathrm{CHC})$ extraction. To account for starvation during the desiccation treatment, we also exposed separate flies to a starvation pre-treatment. This consisted of $3.0 \mathrm{~h}$ and $4.5 \mathrm{~h}$ for male and female flies, respectively, on non-nutritive agar, followed by a $1 \mathrm{~h}$ recovery period on banana-yeast medium. Control flies were kept on banana-yeast medium until CHC extraction.

\subsection{Cuticular hydrocarbon extraction and analysis}

Cuticular hydrocarbons were extracted from 27 control (C), 25 rapid desiccation-hardened (RDH), and 17 starved $(\mathrm{S})$ female flies, and from $28 \mathrm{C}, 25 \mathrm{RDH}$, and $11 \mathrm{~S}$ male flies. Flies were individually aspirated into sterile $400 \mu \mathrm{L}$ borosilicate glass microinserts in $2 \mathrm{~mL}$ vials and washed in $100 \mu \mathrm{L}$ of hexane, containing $10 \mathrm{ng} / \mu \mathrm{L}$ of octadecane $\left(C_{18}\right)$ as an internal standard, for $3 \mathrm{~min}$, followed by vortexing for $1 \mathrm{~min}$ after which the flies were discarded.
Cuticular hydrocarbons were identified and quantified by gas chromatography (method modified from Kwan and Rundle, 2010) using an Agilent 6890N fast gas chromatograph fitted with a HP-5 phenylmethyl siloxane column of $30 \mathrm{~m} \times 250 \mu \mathrm{m}$ internal diameter ( $0.1 \mu \mathrm{m}$ film thickness), a pulsed splitless inlet (at $275^{\circ} \mathrm{C}$ ), and a flame ionization detector (at $310^{\circ} \mathrm{C}$ ). The temperature program began by holding at $140^{\circ} \mathrm{C}$ for $0.55 \mathrm{~min}$, ramping at $120^{\circ} \mathrm{C} / \mathrm{min}$ to $190^{\circ} \mathrm{C}$, slowing to $7{ }^{\circ} \mathrm{C} / \mathrm{min}$ to $260^{\circ} \mathrm{C}$, then ramping at $120^{\circ} \mathrm{C} / \mathrm{min}$ to $310^{\circ} \mathrm{C}$ and holding for $3.5 \mathrm{~min}$. Individual $\mathrm{CHC}$ profiles were determined by integration of the area under 28 peaks in females and 24 peaks in males, representing all those that could be consistently identified in all individuals. The pattern of peaks was broadly consistent with those identified in two previous studies (Everaerts et al., 2010; Foley et al., 2007) using different populations of $D$. melanogaster and chemical identities were assigned with reference to these studies. To correct for technical error associated with quantifying absolute amounts via gas chromatography, relative concentrations were calculated for each $\mathrm{CHC}$ by dividing the area under each peak by the total area of all peaks for a given individual. The resulting proportional values are a form of compositional data to which standard statistical methods should not be applied (Aitchison, 1986; Egozcue and Pawlowsky-Glahn, 2011). To address this and to break the unit-sum constraint also inherent in compositional data, all traits were transformed to log contrast following Aitchison (1986), using the first eluted $\mathrm{CHC},(\mathrm{Z})-9-\mathrm{C}_{21: 1}$, as the common denominator: $\log$ contrast $\mathrm{CHC}_{\mathrm{n}}=\log$ (proportion $\mathrm{CHC}_{\mathrm{n}} /$ proportion $\mathrm{CHC}_{1}$ ); proportions were derived individually for each fly. The choice of peak as the divisor does not affect the statistical analysis or interpretation (Aitchison, 1986).

\subsection{Statistical analysis}

To determine whether there were changes in the relative proportions of CHCs in response to starvation and/or rapid desiccation hardening treatments, multivariate analysis of variances (MANOVAs) were run on the log contrasts values. Log contrasts were visually inspected for multivariate normality and equality of variances, and all assumptions of the MANOVA were satisfied. First, to determine whether there was a starvation effect on CHCs, MANOVAs were run comparing control and starvation treated groups-differences were not significant in either sex and these groups were therefore pooled (see Results). Then, to determine how RDH affected CHCs, MANOVAs of pooled control and starved flies compared to desiccated flies if there were no significant differences between control and starved flies. To determine whether there were differences in proportions of individual CHCs, significant MANOVAs were followed by univariate ANOVAs with a Bonferroni correction, and discriminant function analysis (DFA) to test the predictive power of the MANOVA model. Prior probabilities for DFAs were computed for each treatment from the proportion of total observations for each treatment. All statistical analyses were performed in $\mathrm{R}$ version 3.0.2 (R Development Core Team, 2013).

\section{Results}

The cuticular hydrocarbons quantified in our D. melanogaster samples were comprised of saturated, singly- and doubly-unsaturated, and methyl-branched hydrocarbons (Fig. 1, Table 1). Hydrocarbon chain length varied from 21 to 31 carbons, and there were qualitative differences between the $\mathrm{CHC}$ profiles of males and females (Fig. 1). There was no difference between the $\mathrm{CHC}$ composition of starved and control female (MANOVA, Pillai's Trace $=0.5935, \mathrm{df}=25,18, P=0.4647$ ) or male (MANOVA, Pillai's Trace $=0.6177, \mathrm{df}=23,15, P=0.4695$ ) flies. Thus, $\mathrm{S}$ and $\mathrm{C}$ flies were pooled within each sex for further analysis.

We could successfully discriminate the $\mathrm{CHC}$ composition of RDHtreated flies from their pooled $C$ and $S$ counterparts in both females (MANOVA, Pillai's Trace $=0.5946, \mathrm{df}=25,43, P=0.0037$ ) and males (MANOVA, Pillai's Trace $=0.5285, \mathrm{df}=23,40, P=0.031$ ). Cross- 


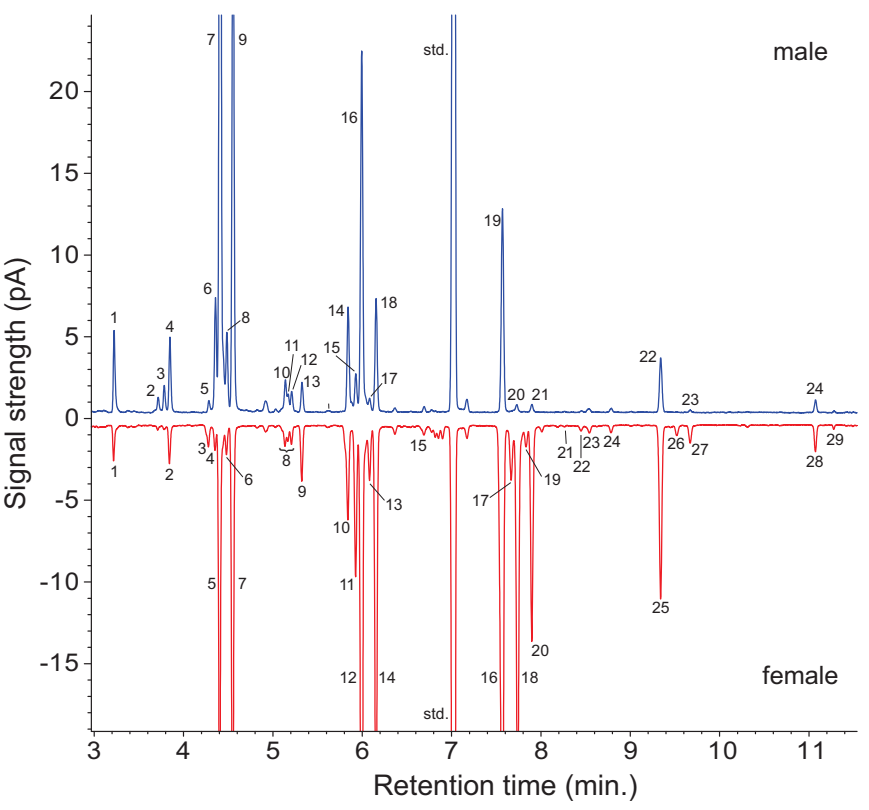

Fig. 1. Representative mirrored chromatograms of cuticular hydrocarbons from male (above) and female (below) D. melanogaster. Putative peak identities are given in Table 1.

validation of the discriminant functions for females and males correctly classified $>65 \%$ of RDH and control/starved flies ( $71 \%$ correct for females, $65.6 \%$ correct for males), which suggests that the RDH pretreatment changes the composition of CHCs in flies of both sexes.

In females, this difference was driven by significantly decreased proportions of $(Z, Z)-7,11-C_{25: 2}, 2-M e-C_{26}$, and $(Z, Z)-7,1-C_{29: 2}$ in the RDH group, along with trends for decreased proportions of $(Z, Z)-7,11-C_{23: 2}$, $(\mathrm{Z}, \mathrm{Z})-7,11-\mathrm{C}_{27: 2}$, and $2-\mathrm{Me}-\mathrm{C}_{30}$ in RDH flies (Fig. 2, Table S2). While not statistically significant in univariate tests, female (but not male)

Table 1

Putative identities of cuticular hydrocarbons ( $\mathrm{CHCs}$ ) of female and male D. melanogaster; numbers refer to peaks in Fig. 1.

\begin{tabular}{|c|c|c|c|}
\hline Female $\mathrm{CHC}$ & Putative identity & Male $\mathrm{CHC}$ & Putative identity \\
\hline 1 & $(Z)-9-C_{21: 1}$ & 1 & $\mathrm{C}_{21}$ \\
\hline 2 & $\mathrm{C}_{22}$ & 2 & $(Z)-9-C_{22: 1}$ \\
\hline 3 & $(Z, Z)-7,11-C_{23: 2}$ & 3 & $(\mathrm{Z})-7-\mathrm{C}_{22: 1}$ \\
\hline 4 & $(Z)-9-C_{23: 1}$ & 4 & $\mathrm{C}_{22}$ \\
\hline 5 & $(Z)-7-C_{23: 1}+(Z, Z)-5,9-C_{23: 2}$ & 5 & $2-\mathrm{Me}-\mathrm{C}_{22}$ \\
\hline 6 & $(Z)-5-C_{23: 1}$ & 6 & $(Z)-9-C_{23: 1}$ \\
\hline 7 & $\mathrm{C}_{23}$ & 7 & $(Z)-7-C_{23: 1}$ \\
\hline 8 & $(Z)-7-C_{24: 1}$ & 8 & $(Z)-5-C_{23: 1}$ \\
\hline 9 & $\mathrm{C}_{24}$ & 9 & $\mathrm{C}_{23}$ \\
\hline 10 & $(Z, Z)-7,11-C_{25: 2}$ & 10 & $(Z)-9-C_{24: 1}$ \\
\hline 11 & (Z) $-9-C_{25: 1}$ & 11 & $(Z)-7-C_{24: 1}$ \\
\hline 12 & $(Z)-7-C_{25: 1}+(Z, Z)-5,9-C_{25: 2}$ & 12 & $(Z, Z)-5,9-C_{24: 2}$ \\
\hline 13 & $(Z)-5-C_{25: 1}$ & 13 & $\mathrm{C}_{24}$ \\
\hline 14 & $\mathrm{C}_{25}$ & 14 & $2-\mathrm{Me}-\mathrm{C}_{24}$ \\
\hline 15 & $(Z, Z)-7,11-C_{26: 2}$ & 15 & $(Z)-9-C_{25: 1}$ \\
\hline 16 & $(Z, Z)-7,11-C_{27: 2}$ & 16 & $(Z)-7-C_{25: 1}$ \\
\hline 17 & 2-Me- $\mathrm{C}_{26}$ & 17 & $(Z)-5-C_{25: 1}$ \\
\hline 18 & $(Z)-7-C_{27: 1}+(Z, Z)-5,9-C_{27: 2}$ & 18 & $\mathrm{C}_{25}$ \\
\hline 19 & $(Z)-5-C_{27: 1}$ & 19 & $2-\mathrm{Me}-\mathrm{C}_{26}$ \\
\hline 20 & $\mathrm{C}_{27}$ & 20 & $(Z)-7-C_{27: 1}$ \\
\hline 21 & $(Z, Z)-9,13-C_{28: 2}$ & 21 & $\mathrm{C}_{27}$ \\
\hline 22 & $(Z, Z)-7,11-C_{28: 2}$ & 22 & $2-\mathrm{Me}-\mathrm{C}_{28}$ \\
\hline 23 & 2-Me- $\mathrm{C}_{28}$ & 23 & $\mathrm{C}_{29}$ \\
\hline 24 & $\mathrm{C}_{28}$ & 24 & $2-\mathrm{Me}-\mathrm{C}_{30}$ \\
\hline 25 & $(Z, Z)-7,1-C_{29: 2}$ & & \\
\hline 26 & $(Z)-7-C_{29: 1}$ & & \\
\hline 27 & $\mathrm{C}_{29}$ & & \\
\hline 28 & $2-\mathrm{Me}-\mathrm{C}_{30}$ & & \\
\hline 29 & $\mathrm{C}_{31}$ & & \\
\hline
\end{tabular}

$\mathrm{RDH}$ flies had consistently higher proportions of all saturated CHCs (C22, C23, C24, C25, C27, C28, C29) compared to the C and S flies. (Tables S2, S3). In male flies, the proportion of 2-Me- $\mathrm{C}_{24}$ was significantly higher in RDH flies than in controls, while the proportion of (Z)-7- $\mathrm{C}_{27: 1}$ was significantly lower in $\mathrm{RDH}$ flies than $\mathrm{C} / \mathrm{S}$ flies (Fig. 2B, Table S3). There was also a trend toward lower proportions of $(Z)-7-C_{22: 1},(Z)-9-C_{23: 1}, 2-M e-C_{26}$, and 2-Me- $C_{30}$ in male RDH flies (Table S3).

\section{Discussion}

We show that rapid desiccation hardening leads to a coordinated change in the $\mathrm{CHC}$ profile of female $D$. melanogaster toward greater saturation and reduced methyl chains in the cuticular lipids. While males also change their $\mathrm{CHC}$ profile after a desiccation pre-treatment, this response is not as coordinated as in females, and does not have the same bias toward $\mathrm{CHC}$ species expected to decrease cuticular permeability. This is consistent with the observation that only female $D$. melanogaster reduce CWL in response to $\mathrm{RDH}$ (Bazinet et al., 2010), and suggests that a change in $\mathrm{CHC}$ profile may be the mechanism underlying reduced CWL in the RDH response. This response is specific to dehydration: the $\mathrm{CHC}$ profiles of starved flies were indistinguishable from untreated controls. Given that rapid desiccation hardening in response to acute desiccation stress occurs in female $D$. melanogaster via a change in cuticular CHCs, the mechanism by which the cuticular lipids are altered remains unknown. Further study is needed to determine whether the changes in CHCs due to acute desiccation stress occur during the desiccation stress, or during the recovery from stress. Kwan and Rundle (2010) found a change in CHCs extracted from females immediately after desiccation, suggesting that desiccation-responsive $\mathrm{CHC}$ modifications have at least begun during that time window, and Petfield et al. (2005) show that CHCs can change in a timespan of minutes in response to social interactions. In addition, it is unclear how the CHCs are altered during RDH; possible (non-mutually-exclusive) mechanisms include secretion of new lipids onto the cuticle (Wigglesworth, 1975; Pennanec'h et al., 1997), or secretion of extracellular enzymes (Oakeshott et al., 2005 ) to saturate/demethylate (or selectively degrade) existing CHCs.

Our results suggest that an acute change in the $\mathrm{CHC}$ composition of CHCs can be enough to have dramatic effects on whole-organism physiology, e.g. reduced CWL and enhanced desiccation tolerance. Kalra et al. (2014) found that total quantity of CHCs does not change under RDH in a variety of species, which suggests that total CHC quantity does not occur in the RDH response. Ramniwas et al. (2013) show that desiccation resistance is increased and CWL is reduced during selection for increased melanisation, and Parkash et al. (2009a, 2009b) found similar results among different populations of $D$. melanogaster. Total CHCs did not change in either study, and the implicit assumption was that melanisation was primarily responsible for the change in CWL rates and desiccation survival (Parkash et al., 2009a, 2009b; Ramniwas et al., 2013); however, CHC profiles were not measured. Similarly, in tsetse flies, total CHCs were unable to explain differences in desiccation rates among populations (Jurenka et al., 2007), implying that some other mechanism must differ among populations (e.g. cuticular melanisation, changes in $\mathrm{CHC}$ profile). Our results, in combination with those of Bazinet et al. (2010) and Kalra et al. (2014), suggest that changes in the $\mathrm{CHC}$ profile, not $\mathrm{CHC}$ quantity, can have strong impacts on CWL rates and desiccation resistance-this means that if melanisation and $\mathrm{CHC}$ profiles are linked, the enhanced desiccation resistance of melanised flies observed by Ramniwas et al. (2013) could, in part, be due to altered $\mathrm{CHC}$ profiles. Further, total $\mathrm{CHC}$ mass in D. melanogaster does not show a plastic response to changes in developmental growth temperature (Parkash et al., 2013), developmental humidity conditions (Aggarwal et al., 2013), and acute desiccation response (Kalra et al., 2014). This would suggest that total CHCs in D. melanogaster cannot explain changes in desiccation resistance, and indeed this was observed by Parkash et al. (2011). Melanisation is 


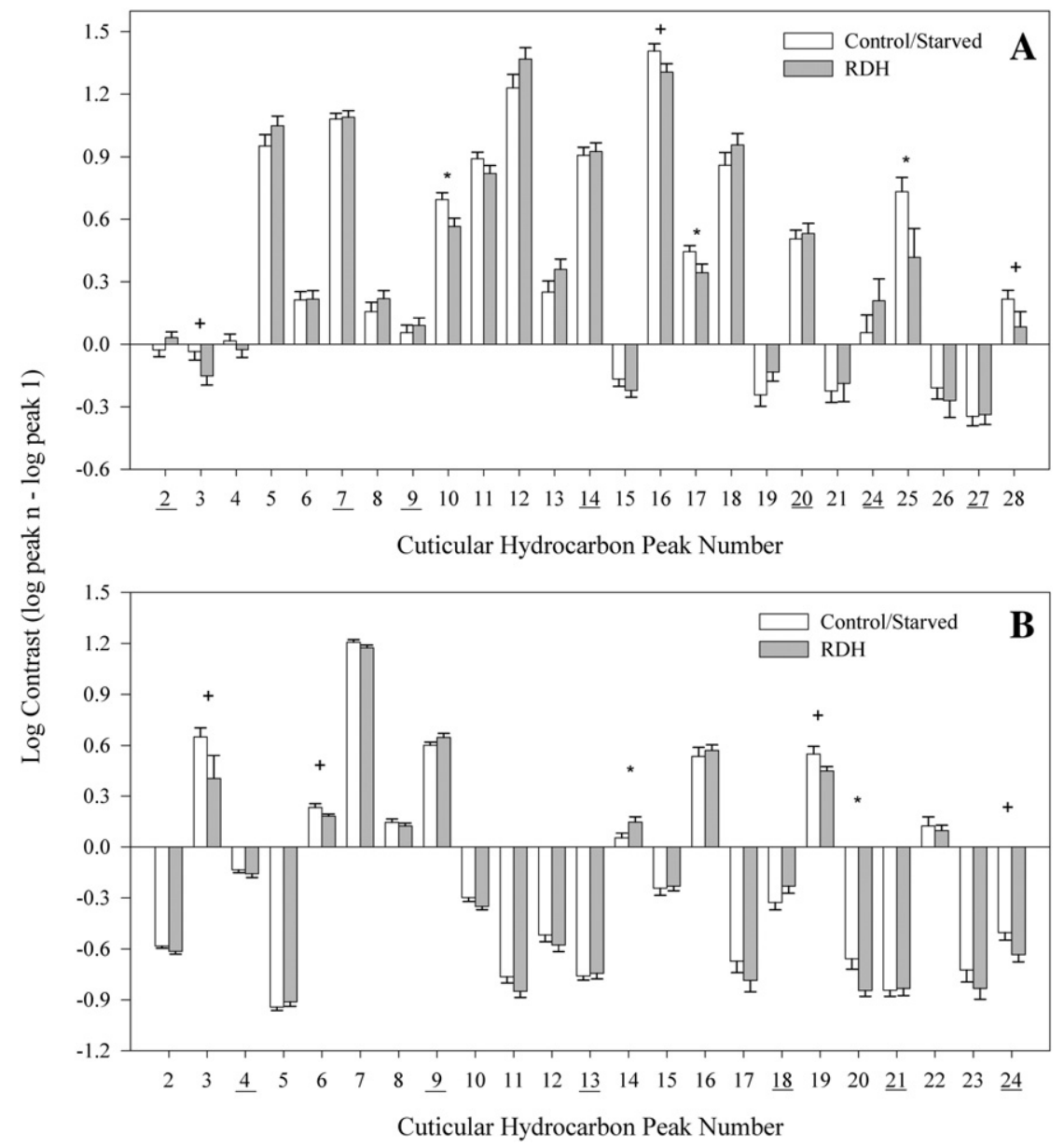

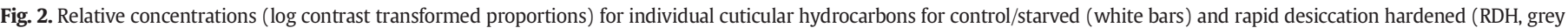

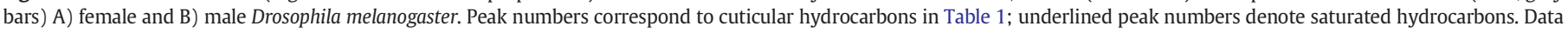

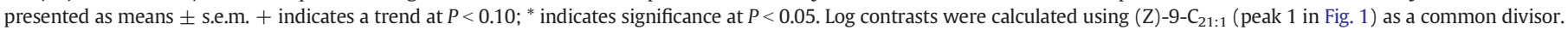
For further details on statistics and signs of log contrasts, see Table S2 and S3.

positively correlated with desiccation tolerance and negatively correlated with CWL in D. melanogaster (Parkash et al., 2011; Parkash and Aggarwal, 2012; Kalra et al., 2014). However cuticular melanisation is determined during development (Gibert et al., 2000; Parkash et al., 2013), and may evolve (see Parkash et al., 2011, and Parkash and Aggarwal, 2012, for among-population differences), but is unlikely to change in response to acute desiccation stress and thus cannot explain short-term variation in CWL (Aggarwal et al., 2013; Kalra et al., 2014). By contrast, the changes in $\mathrm{CHC}$ profile in response to $\mathrm{RDH}$ that we observed would be consistent with a rapid decrease in CWL. While CHC production is complex (Howard and Blomquist, 2005), the rapid plasticity we observed in CHCs could involve multiple mechanisms at genetic-, protein-, or behavioural-levels, and all of which could bias experiments where this rapid plasticity might be induced (e.g. pre-treatment desiccates flies and induces RDH).

The rapid plasticity in CHCs that we observed may help to explain the reversibility of the RDH response reported by Hoffmann (1990, 1991). Hoffmann $(1990,1991)$ demonstrated that the RDH response that occurs in females of $D$. melanogaster, Drosophila immigrans, Drosophila simulans, and Drosophila serrata persists for at least $24 \mathrm{~h}$; however, desiccation survival returns to control levels after [48 to $53 \mathrm{~h}$ ]. Because the $\mathrm{CHC}$ composition can be changed rapidly to reduce $\mathrm{CWL}$, we expect that it should also be able to be modified back to the nonacclimated state. If the reversibility of RDH is dependent on CHC composition, then it implies that there are costs to the wholesale modification of the $\mathrm{CHC}$ profile.
In D. melanogaster, $\mathrm{CHCs}$ also act as pheromones that are involved sex and species recognition, as well as in courtship, with demonstrated stimulation and inhibitory roles (Billeter et al., 2009; Chertemps et al., 2006; Coyne et al., 1994; Ferveur, 2005; Grillet et al., 2006; Rybak et al., 2002; Savarit and Ferveur, 2002). Changes in CHCs in response to $\mathrm{RDH}$ may therefore have reproductive consequences including altered mating success. In particular, differences in 7,11 dienes and 7 monoenes of females can affect male courting behaviour (Antony et al., 1985; Chertemps et al., 2006) and our results show that several 7,11 dienes decreased in proportion in the cuticle after RDH in females. Such changes may allow males to select for or against females based on their previous exposure to desiccation stress, and/or allow females to signal enhanced desiccation tolerance. In addition, in males the importance of $\mathrm{CHCs}$ as sexual displays that affect attractiveness to females has been well established in multiple Drosophila species (e.g., Chenoweth and Blows, 2005; Van Homrigh et al., 2007; Curtis et al, 2013; Chung et al., 2014; Dyer et al., 2014). Sexual selection on CHCs may therefore be antagonistic to desiccation hardening responses, as well as longer-term adaptation to desiccation stress (e.g., Kwan and Rundle, 2010), potentially explaining the reduced response in males in both of these contexts. Further work is needed to determine whether acute changes in CHC composition are a general mechanism for increasing short-term desiccation tolerance in other Drosophila and whether other species also show sex-specific patterns of RDH. With respect to the latter, tests of the effects of these $\mathrm{CHC}$ changes on mating success may provide insight into constraints on $\mathrm{RDH}$ expression. 


\section{Acknowledgements}

Thanks to B. Rubin and K. Marshall for advice on statistical analysis; D. Arbuthnott and J. Sztepanacz for help with the gas chromatography; and L.V. Ferguson and two anonymous referees for feedback on the manuscript. This research was supported by the Natural Science and Engineering Research Council of Canada via USRA scholarships to JRS and RJS, and Discovery Grants to BJS and HDR.

\section{Appendix A. Supplementary data}

Supplementary data to this article can be found online at http://dx. doi.org/10.1016/j.cbpa.2014.11.004.

\section{References}

Aggarwal, D.D., Ranga, P., Kalra, B., Parkash, R., Rashkovetsky, E., Bantis, L.E., 2013. Rapid effects of humidity acclimation on stress resistance in Drosophila melanogaster. Comp. Biochem. Physiol. 166A, 81-90.

Aitchison, J., 1986. The Statistical Analysis of Compositional Data. Chapman and Hall, London, U.K.

Antony, C., Davis, T., Carlson, D., Pechine, J.-M., Jallon, J.-M., 1985. Compared behavioural responses of male Drosophila melanogaster (Canton S) to natural and synthetic aphrodisiacs. J. Chem. Ecol. 11, 1617-1629.

Bazinet, A., Marshall, K.E., MacMillan, H.A., Williams, C.M., Sinclair, B.J., 2010. Rapid changes in desiccation resistance in Drosophila melanogaster are facilitated by changes in cuticular permeability. J. Insect Physiol. 56, 2006-2012.

Billeter, J.C., Atallah, J., Krupp, J.J., Millar, J.G., Levine, J.D., 2009. Specialized cells tag sexual and species identity in Drosophila melanogaster. Nature 461, 987-992.

Chenoweth, S.F., Blows, M.W., 2005. Contrasting mutual sexual selection on homologous signal traits in Drosophila serrata. Am. Nat. 165, 281-289.

Chertemps, T., Duportets, L., Labeur, C., Ueyama, M., Wicker-Thomas, C., 2006. A female-specific desaturase gene responsible for diene hydrocarbon biosynthesis and courtship behaviour in Drosophila melanogaster. Insect Mol. Biol. 15, 465-473.

Chung, H., Loehlin, D.W., Dufour, H.D., Vaccarro, K., Millar, J.G., Carroll, S.B., 2014. A single gene affects both ecological divergence and mate choice in Drosophila. Science 343, $1148-1151$.

Coyne, J.A., Crittenden, A.P., Mah, K., 1994. Genetics of a pheromonal difference contributing to reproductive isolation in Drosophila. Science 265, 1461-1464.

Curtis, S., Sztepanacz, J.L., White, B.E., Dyer, K.A., Rundle, H.D., 2013. Epicuticular compounds of Drosophila subquinaria and D. recens: identification, quantification, and their role in female mate choice. J. Chem. Ecol. 39, 579-590.

Dyer, K.A., White, B.E., Sztepanacz, J.L., Bewick, E.R., Rundle, H.D., 2014. Reproductive character displacement of epicuticular compounds and their contribution to mate choice in Drosophila subquinaria and Drosophila recens. Evolution 68, 1163-1175.

Egozcue, J.J., Pawlowsky-Glahn, V., 2011. Basic concepts and procedures. In Pawlowsky-Glahn, V., Buccianti, A. (Eds.), Compositional Data Analysis: Theory and Applications. John Wiley \& Sons, Chichester, U.K.

Everaerts, C., Farine, J., Cobb, M., Ferveur, J., 2010. Drosophila cuticular hydrocarbons revisited: mating status alters cuticular profiles. PLoS One 5.

Ferveur, J.-F., 2005. Cuticular hydrocarbons: their evolution and roles in Drosophila pheromonal communication. Behav. Genet. 35, 279-295.

Foley, B., Chenoweth, S., Nuzhdin, S.V., Blows, M., 2007. Natural genetic variation in cuticular hydrocarbon expression in male and female Drosophila melanogaster. Genetics 175, 1465-1477.

Gibbs, A.G., 2002. Lipid melting and cuticular permeability: new insights in an old problem. J. Insect Physiol. 48, 391-400.

Gibbs, A.G., Pomonis, J.G., 1995. Physical properties of insect cuticular hydrocarbons: the effects of chain length, methyl-branching and unsaturation. Comp. Biochem. Physiol. 112B, 243-249.

Gibbs, A.G., Chippendale, A.K. Rose, M.R., 1997. Physiological mechanisms of evolved desiccation resistance in Drosophila melanogaster. J. Exp. Biol. 200, 1821-1832.

Gibert, P., Moreteau, B., David, J.R., 2000. Developmental constraints on an adaptive plasticity: reaction norms of pigmentation in adult segments of Drosophila melanogaster. Evol. Dev. 2, 249-260.
Grillet, M., Dartevelle, L., Ferveur, J.F., 2006. A Drosophila male pheromone affects female sexual receptivity. Proc. R. Soc. B 273, 315-323.

Hadley, N.F., 1978. Cuticular permeability of desert tenebrionid beetles: correlations with epicuticular hydrocarbon composition. Insect Biochem. 8, 17-22.

Hadley, N.F., 1994. Water Relations of Terrestrial Arthropods. Academic Press, San Diego

Hiruma, K., Riddiford, L.M., 1988. Granular phenoloxidase involved in cuticular melanization in the tobacco hornworm: regulation of its synthesis in the epidermis by juvenile hormone. Dev. Biol. 130, 87-97.

Hoffmann, A.A., 1990. Acclimation for desiccation resistance in Drosophila melanogaster and the association between acclimation responses and genetic variation. J. Insect Physiol. 36, 885-891.

Hoffmann, A.A., 1991. Acclimation for desiccation resistance in Drosophila-species and population comparisons. J. Insect Physiol. 37, 757-762.

Howard, R.W., Blomquist, G.J., 2005. Ecological, behavioral, and biochemical aspects of insect hydrocarbons. Annu. Rev. Entomol. 50, 371-393.

Jurenka, R., Terblanche, J.S., Klok, C.J., Chown, S.L., Krafsur, E.S., 2007. Cuticular lipid mass and desiccation rates in Glossina pallidipes: interpopulation variation. Physiol Entomol. 32, 287-293.

Kalra, B., Parkash, R., Aggarwal, D.D., 2014. Divergent mechanisms for water conservation in Drosophila species. Entomol. Exp. Appl. 151, 43-56.

Kwan, L., Rundle, H.D., 2010. Adaptation to desiccation fails to generate pre- and postmating isolation in replicate Drosophila melanogaster laboratory populations. Evolution $64,710-723$.

Marshall, K.E., Sinclair, B.J., 2010. Repeated stress exposure results in a survivalreproduction trade-off in Drosophila melanogaster. Proc. R. Soc. B 277, 963-969.

Oakeshott, J., Claudianos, C., Campbell, P., Newcomb, R., Russell, R., 2005. Biochemical genetics and genomics of insect esterases. In: Gilbert, L., Iatrou, K., Gill, S. (Eds.) Comprehensive Molecular Insect Science vol. 5. Elsevier, Oxford, UK, pp. 309-381.

Parkash, R., Aggarwal, D.D., 2012. Trade-off of energy metabolites as well as body color phenotypes for starvation and desiccation resistance in montane populations of Drosophila melanogaster. Comp. Biochem. Physiol. 161A, 102-113.

Parkash, R., Kalra, B., Sharma, V., 2008. Changes in cuticular lipids, water loss and desiccation resistance in a tropical drosophilid. Fly 2, 189-197.

Parkash, R., Rajpurohit, S., Ramniwas, S., 2009a. Impact of darker, intermediate and lighte phenotypes of body melanization on desiccation resistance in Drosophila melanogaster. J. Insect Sci. 9, 1-10.

Parkash, R., Sharma, V., Kalra, B., 2009b. Impact of body melanisation on desiccation resistance in montane populations of $D$. melanogaster: analysis of seasonal variation. J. Insect Physiol. 55, 898-908.

Parkash, R., Aggarwal, D.D., Kalra, B., Ranga, P., 2011. Divergence of water balance mechanisms in two melanic Drosophila species from the western Himalayas. Comp. Biochem. Physiol. 158A, 531-541.

Parkash, R. Aggarwal, D.D., Singh, D., Lambhod, C. Ranga, P., 2013. Divergence of wate balance mechanisms in two sibling species (Drosophila simulans and D. melanogaster): effects of growth temperatures. J. Comp. Physiol. 183B, 359-378.

Pennanec'h, M., Bricard, L., Kunesch, G., Jallon, J.-M., 1997. Incorporation of fatty acids into cuticular hydrocarbons of male and female Drosophila melanogaster. J. Insect Physiol. $43,1111-1116$.

Petfield, S., Chenoweth, S.F., Rundle, H.D., Blows, M.W., 2005. Genetic variance in female condition predicts indirect genetic variance in male sexual display traits. Proc. Natl. Acad. Sci. U. S. A. 102, 6045-6050.

R Development Core Team, 2013. R: a language and environment for statistical computing. R Foundation for Statistical Computing, Vienna, Austria.

Ramniwas, S., Kajla, B., Dev, K., Parkash, R., 2013. Direct and correlated responses to laboratory selection for body melanisation in Drosophila melanogaster: support for the melanisation-desiccation resistance hypothesis. J. Exp. Biol. 216, 1244-1254.

Rybak, F., Sureau, G., Aubin, T., 2002. Functional coupling of acoustic and chemical signals in the courtship behaviour of the male Drosophila melanogaster. Proc. R. Soc. B 269, 695-701.

Savarit, F., Ferveur, J.F., 2002. Genetic study of the production of sexually dimorphic cuticular hydrocarbons in relation with the sex-determination gene transformer in Drosophila melanogaster. Genet. Res. 79, 23-40.

Schimpf, N.G., Matthews, P.G.D., Wilson, R.S., White, C.R., 2009. Cockroaches breathe discontinuously to reduce respiratory water loss. J. Exp. Biol. 212, 2773-2780.

Terblanche, J.S., Clusella-Trullas, S., Chown, S.L., 2010. Phenotypic plasticity of gas exchange pattern and water loss in Scarabaeus spretus (Coleoptera: Scarabaeidae) deconstructing the basis for metabolic rate variation. J. Exp. Biol. 213, 2940-2949.

Van Homrigh, A., Higgie, M., McGuigan, K., Blows, M.W., 2007. The depletion of genetic variance by sexual selection. Curr. Biol. 17, 528-532.

Wigglesworth, V.B., 1975. Incorporation of lipid into the epicuticle of Rhodnius (Hemiptera). J. Cell Sci. 19, 459-485. 